ampicillin again for a different disease or as a test dose after recovery from glandular fever. 45 Furthermore, the eruption seems to be dose-related ${ }^{6-8}$ and is not suppressed by corticosteroids. ${ }^{9}$ Attempts to find reaginic antibodies failed ${ }^{3}$ and lymphocyte transformation tests were negative. ${ }^{10}$

Cameron and Richmond emphasize that patients with lymphatic leukaemia are particularly susceptible to bacterial infection, as are patients with infectious mononucleosis, and suggest that they should be given a sulphonamide-trimethoprim combination, erythromycin, or tetracycline pending bacteriological sensitivity reports. However, no broadspectrum antibiotic apart from ampicillin is contraindicated in these conditions. Though the mechanism of this troublesome reaction to ampicillin remains a mystery its occurrence is at least helpful in suggesting the presence of infectious mononucleosis or lymphatic leukaemia.

\footnotetext{
1 Shapiro, S., Siskind, V., Slone, D., Lewis, G. P., and Jick, H., Lancet, $1969,2,969$.

2 Cameron, S. J., and Richmond, J., Scottish Medical fournal, 1971, 16, 425.

3 Knudsen, E. T., British Medical fournal, 1969, 1, 846.

Crow, K. D., Transactions of the St. Fohn's Hospital Dermatological Society, 1970, 56, 35 .

5 Haider, S. A., British Medical fournal, 1971, 4, 364.

- Lancet, 1969, 2, 993.

7 Levine, B. B., and Ovary, Z., fournal of Experimental Medicine, 1961, 114, 875.

8 Patel, B. M., Pediatrics, 1967, 40, 910.

- Pullen, H., Wright, H., and Murdoch, T. McC., Lancet, 1967, 2, 1176

10 Sarkany, I., Proceedings of the Royal Society of Medicine, 1968, 61, 891.
}

\section{Head Injuries in Children}

Accidents are now a major cause of death in infants and children, and in schoolchildren they are the commonest single cause. Of all accidental deaths the greatest number are due to head injury. ${ }^{1}$ Apart from birth trauma, the mechanics of most of the head injuries are similar to those occurring in young and middle-aged adults. The intracranial lesions are also similar except for the true subdural haematoma of infancy, the widespread haemorrhage into the subarachnoid space without subdural haematoma, and the phenomenon of benign intracranial hypertension.

The cause of benign intracranial hypertension is still obscure. Thrombosis of the lateral venous sinus has been implicated, ${ }^{2}$ particularly when associated with middle ear infection, but why benign intracranial hypertension should develop after a relatively minor head injury is not known. In a recent review of 79 cases of benign intracranial hypertension D. N. Grant ${ }^{3}$ noted only three children in whom the onset seemed related to previous head injury. This unusually low incidence probably reflects the work of a particular neurosurgical depantment rather than the true incidence of the condition.

The ventricular system was visualized in 75 of Grant's patients by either air ventriculogram or lumbar air encephalogram: in 63 the ventricular system was normal and in eight there was dilatation. This important observation refutes a widely held belief that ventricles tend to be narrowed and compressed by an oedematous brain. Subtemporal decompression or suboccipital craniectomy is seldom needed because of deteriorating vision and it is uncertain whether lumbar puncture is truly therapeutic. ${ }^{3}$ In only $54 \%$ of Grant's cases had the fundi become normal at six months, but in post-traumatic cases of benign intracranial hypertension most neurosurgeons, provided the child is otherwise well, would accept the diagnosis, continue outpatient observation, and avoid unnecessary air studies.

A prognosis is now more often asked for in children still unconscious after a severe head injury. Skilled intensive-care treatment directly improves the chances of survival, but an opinion on ultimate disability and the prospects of a return to school may be difficult to give. O. Heiskanen and P. Sipponen ${ }^{4}$ found that in 62 patients aged under 20 with severe head injury (with a mortality of $32 \%$ ) coma of up to four weeks duration in those who survived beyond three years did not of itself prevent rehabilitation for work or return to school. The implications of this for prognosis and for intensive care effort in children and adolescents are important.

Children who have sustained a minor head injury are the most likely to present problems in later management, particularly in relation to psychiatric or behavioural disorders. D. A. Pond ${ }^{5}$ concluded that there were no psychological tests of more than general statistical value and that there was no unequivocal clinical sign or physiological test which related brain damage and any particular form of disturbed behaviour. Earlier studies ${ }^{6}$ had emvhasized the relevance of parental attitudes and environment when attempting to ascribe psychiatric symptoms and behavioural disturbances accurately to previous head injury.

These observations are confirmed by V. Rune in a recent survey of primary school children in the Swedish city of Umeâ. 7 This showed that psychiatric symptoms or problems of adiustment occurred after a minor head injury only in children whose environment was unsatisfactory or who had previously had psychiatric or behavioural disorders. Intracranial abnormality will probably not be found in such children unless there was overt neurological damage in the acute stage after the iniury, and these children will be easier to manage if they are not subiected to complex and perhaps unpleasant intracranial investigations.

1 Matson, D. D., Neurosurgery of Infancy and Childhood, 2nd end. Springfield, Illinois, Thomas, 1969

2 Symonds, C. P., Brain, 1931, 54, 55

2 Symonds, C. P., Brain, 1931, 54, 55. Children, 1971, 46, 651.

- Heiskanen, O., and Sipponen, P., Acta Neurologica Scandinavica, 1970, 46, 343.

5 Pond, D. A., in Modern Trends in Neurology-4, ed. D. Williams. London, Butterworths, 1967.

- Harrington, J. A., and Letemendia, F. J. J., fournal of Mental Science, $1958,104,1205$.

7 Rune, V., Acta Paediatrica Scandinavica, 1970, Supplement 209.

\section{Surgery in Rheumatoid Arthritis}

Surgery in the management of rheumatoid arthritis may be early, to try to prevent further damage; intermediate, to preserve function so far as possible; or late, to reconstruct or fuse severely damaged joints. In a disease with an insidious onset and fluctuating course it is difficult to define "early." Synovectomy as a prophylactic procedure should be undertaken before irreversible changes occur in the articular cartilage. In practical terms early synovectomy is considered in adults when synovial thickening in a joint or tendon sheath with pain or loss of function persists after three to four months' medical treatment. In children, in whom the disease has a greater tendency to remit and erosive changes begin later, a period of 18 months before synovectomy has been suggested, unless function is deteriorating. ${ }^{1}$ 